\title{
The Pandemic of Productivity: A Narrative Inquiry into the Value of Leisure Time
}

\author{
Jessica S. Klaver * and Wim Lambrechts (D)
}

check for updates

Citation: Klaver, J.S.; Lambrechts, W. The Pandemic of Productivity: A Narrative Inquiry into the Value of Leisure Time. Sustainability 2021, 13, 6271. https://doi.org/10.3390/ su13116271

Academic Editors: Cinzia Castiglioni and Edoardo Lozza

Received: 14 April 2021

Accepted: 27 May 2021

Published: 1 June 2021

Publisher's Note: MDPI stays neutral with regard to jurisdictional claims in published maps and institutional affiliations.

Copyright: (c) 2021 by the authors. Licensee MDPI, Basel, Switzerland. This article is an open access article distributed under the terms and conditions of the Creative Commons Attribution (CC BY) license (https:/ / creativecommons.org/licenses/by/ $4.0 /)$.
Department of Marketing \& Supply Chain Management, Open Universiteit, 6401 DL Heerlen, The Netherlands; wim.lambrechts@ou.nl

* Correspondence: Jessica.klaver@ou.nl

\begin{abstract}
This study explored narratives derived from in-depth interviews to demonstrate how an increase in leisure time could positively affect both our subjective well-being, through a better balance of work and "self", and the environment, through a change in consumption practices. Firstly, the analysis of the interviews provided insight into the social function of work. Work creates feelings of connection and belonging; however, it can also create the opposite, negatively affecting our experience of leisure time, our productivity, and our well-being. Participants described how paid work provided structure and routine, which resulted in an increased feeling of subjective wellbeing. However, a lack of structure and routine during the COVID-19 pandemic negatively affected feelings of "usefulness" and "productivity". Secondly, an increase in leisure time created more opportunities for autonomy, leading to more unforced leisure activities and a better balance between work and self. Moreover, an increase in autonomy could be achieved through both increased work flexibility and a shorter working week. Lastly, this study aimed to demonstrate that more leisure time during lockdown periods can change how we spend our free time, therefore resulting in more pro-environmental consumer behaviour. This study intended to contribute to a gap in the literature: effects of leisure time on the balance between work and the "self". The research setting offered limited opportunities for researching intentional, sustainable consumer behaviour, which provides an opportunity for further research.
\end{abstract}

Keywords: sustainable consumption; future of work; COVID-19; leisure time; narrative inquiry

\section{Introduction}

The COVID-19 lockdown created a unique research environment: most people's worklife routines drastically changed as offices had to close and social events and opportunities for consumption or interaction became limited or were even prohibited. Moreover, national lockdowns forced people to give up some of their most deeply ingrained habits. In a "business as usual" scenario, hours gained through a restructuring or disappearance of work are absorbed by either social or consumer activities [1]. However, this "new-normal" meant that this sudden increase in leisure time had to be spent differently.

Even though the COVID-19 pandemic provided this study with a unique research environment, the study did not aim to capture people's feelings and worries about the virus or the lockdown itself. The intention of this research project was to move beyond these fears and, instead, capture the participants' experience of leisure time and work during this global phenomenon.

Research has shown how lockdown measures can have various negative effects, e.g., increased feelings of stress and isolation, struggles related to working from home, financial insecurity, and etc. [2]. This study, however, aimed to demonstrate how an increase in leisure time can positively affect both our subjective well-being, through a better balance of work and "self", and the environment, through a change in consumption.

The first Human Development Report of 1990 began with a simple [statement]: "development is about enlarging people's choices and focusing broadly on the richness of human 
lives rather than narrowly on the richness of economies" [3] (p. 3). Under the influence of the COVID-19 pandemic, the human development statement demands the question: are we still focusing on what matters? Regarding sustainable development, the focus should lie on changing how we consume in the developed world, emphasising "needs" rather than "wants" and encouraging consumers to make more informed, sustainable purchases instead of those influenced by (social) media or dictated by the fashion.

This study aimed to propose further development of policies for "downshifting", i.e., a voluntary decrease in working hours to increase leisure time, improve well-being, and simultaneously benefit the environment. "Downshifting" could offer individuals a possible solution to work-related stress, both physical and mental, which could, in return, improve one's quality of life [4]. However, downshifting can also be criticised insofar as it is a discursive strategy with little emancipatory potential [5]. This study aimed to highlight the benefits of increased leisure time, using the COVID-19 lockdown as the research setting. What did this global phenomenon teach us about the value of time, and what could this mean for the future of work and consumption post-COVID-19?

This study intended to contribute to a gap in the literature: the effects of leisure time on the balance between work and the "self". The analysis of the in-depth interviews conducted for this study was guided by the following questions. Firstly, how did participants spend their time during the COVID-19 lockdown, and how has this changed their perspectives about time spent working and time spent living? Secondly, this paper aimed to gain more insight into how the COVID-19 lockdown has changed the balance between work and the "self", and how this could change the future of work. Lastly, this paper was concerned with how a shorter or more flexible work week could simultaneously benefit the balance between work and self, and the environment.

\section{Theoretical Framework}

A vast body of literature addresses the connection between working hours, human well-being, and consumer behaviour. The topic of working hours and its various associations has been prominent in academic research for several decades. Moreover, the literature on consumption is well-stocked with "different approaches to consumption and different models of how consumers behave" [6] (p. 21).

\subsection{Research into Consumption}

Research into consumer culture dates back to the late 19th century with Veblen's theory of "Conspicuous Consumption", which offers a critique of the neoclassical theory of consumption and describes social classes' desire to gain the status of those just above them. This status comes with specific patterns of consumption [7]. One critique of Veblen's theory is that "conspicuous consumption lacks generality as a theory of consumption since it applies only to luxury goods" [7] (p. 99). However, Veblen identified two main ways people choose to display their wealth: through consumption, a waste of goods, and through leisure activities, a waste of time and effort [7]. Today, social bonds on a community level are not as strong as those in the 19th century. Therefore, the presentation of wealth through consumption has become more effective and more critical than the display of leisure [7]. Time off used to be a status symbol, whereas today, being busy and overworked is the reality for many. Moreover, this reality comes with competitive busyness [8]. How individuals relate to ideas of time, both valuing and wasting time, and how they experience the pursuit of busyness and productivity is discussed later on in this paper.

Conspicuous consumption emphasises the individual and the rationale of individual consumer choices. Similarly, "Nudge Theory" is aimed at the individual consumer. Thaler and Sunstein [9] stated that, by knowing how they think, people can be "nudged" towards choices that will better themselves, society, and the environment. Mary Douglas [10] further stated that "an individual's main objective in consumption is to help create the social world and find a credible place in it" (quoted in [6] (p. 5)). Therefore, in this 
approach, consumption is primarily a social process and a symbolic action rather than the "drive to meet basic needs such as food, shelter, or clothing" [11] (pp. 3-4).

\subsection{High-Growth Economies and Environmental Degradation}

Schor [11] stated that fast-growing economies have high productivity growth, which often leads to higher salaries rather than extra leisure time. "Being busy" has become the primary symbolic source of "a full and valued life" [1] (p. 6). On the other hand, psychological literature shows how this upsurge in materialist values due to higher salaries and a lack of leisure time are negatively correlated with well-being [11]. High-growth economies and time-deprived lifestyles fail to provide us with the foundation for a fulfilling life, but how does it affect our planet?

The Environmental Kuznets Curve (EKC) theory posits a link between economic development and environmental degradation and demonstrates that environmental degradation increases up to a point as economies grow and "decreases as income exceeds a threshold level". [12] (p. 85). Therefore, it suggests that economic development can be achieved without further environmental degradation or even in combination with ecological sustainability [12]. However, there is disagreement among critics about the potential of economic growth to benefit environmental degradation. Unrestrained growth is, in fact, the source, not the solution, of environmental degradation. Moreover, research demonstrates its contribution to social inequality and decreased quality of life [13].

Neo-Marxists have concentrated their research on environmental sociology regarding the "treadmill of production" [14]. The focus here lies on the "continuity of the capitalist character of modern production and consumption systems", which are damaging the natural capital that supports these systems [15] (p. 540). Studies in this tradition indicate how production and consumption structures need transforming, as they contain inherently capitalist patterns of "accumulation and exploitation". As long as this "industrial-capitalist character of production-consumption systems" remains, the environment will suffer the consequences [15] (p. 540). Therefore, the question is: can we change the dominant consumption culture inherent in our industrial-capitalist society by adopting radically different lifestyles that focus more on the value of time rather than the accumulation of things?

\subsection{Pro-Environmental Consumer Behaviour}

While ecological degradation seems primarily driven by "production", this approach ignores that all production is carried out with the purpose of consumption. Until the early nineties, much of the research done regarding sustainable consumption focused on the side of the producer, with relatively few studies considering or focusing primarily on the consumer [16]. Since then, attention towards the consumer perspective has increased considerably within the fields of consumer research, marketing, and (environmental) psychology [17-20]. For example, Dietz et al. [21] highlighted two lines of reasoning within the field of environmental values. On the one hand, according to the ValuesBeliefs-Norms (VBN) theory, certain values (such as altruism), beliefs (such as ecological worldview), and personal norms influence pro-environmental behaviour. On the other hand, the focus has been set on postmaterialist theory, assuming that when basic needs are met, one has more attention towards environmental concerns and is inclined to engage in pro-environmental behaviours [21].

Continued increases in consumption are not compatible with sustainable development, considering that "current rates of resource use are already exceeding sustainable levels" [22] (p. 8). Only when some or all of the increased labour productivity results in increased leisure time will environmental benefits rise [23]. One way to increase leisure time is by voluntarily reducing working hours and thereby income, which has been referred to in the literature as "downshifting" or "a Voluntary Simplicity Lifestyle" [4,24,25]. These terms refer to a decrease in working hours and an increase in leisure time, which could offer individuals a possible solution to work-related stress, both physical and mental, and, 
in return, improve quality of life [26]. Furthermore, a voluntary shift to shorter working hours could also provide environmental payoffs: on the one hand, a lower income reduces total consumption; on the other hand, more leisure time weakens materialist values, thereby creating greater mindfulness about how we consume [4].

Without a decrease in absolute working hours, and thereby income, most consumers will not change how much they consume. Instead, the focus of the environmentallyconscious consumer may shift towards "green" consumption in an attempt to engage in more altruistic behaviour [27]. In reference to Veblen's theory of "conspicuous consumption", products have both a utilitarian and symbolic function [7]. Consumers may therefore also choose to adopt "green" purchasing behaviour in an attempt to display their social status. Consumer research has demonstrated this link between peer opinions and green purchasing behaviour [28-30]. "Sustainable" consumption requires that people consume less, which requires intervention at a preventative level, whereas the aim of "green" consumerism is not to change the system but simply to change the products that are being made and consumed, which directs the pressure to drive "the system towards sustainability" toward the consumer [27] (p. 16).

The question of what shapes pro-environmental behaviour is a complex one that "cannot be visualised through one single framework or diagram" [31] (p. 239). Steg and Vlek [32] indicated four key issues for encouraging pro-environmental behaviour: (1) the behaviours that need to be changed; (2) factors influencing relevant behaviour; (3) interventions needed to encourage pro-environmental behaviour; and (4) the effects of such interventions. Regarding values underlying pro-environmental behaviour, it is generally believed that people adhering to altruistic or biospheric values are more engaged in pro-environmental behaviour, while extrinsically motivated people with a strong competitive orientation are less likely to make pro-environmental choices [21,31,32]. In line with postmaterialist theory, Kollmuss and Agyeman [31] claimed that once people have "satisfied their personal needs", they are more likely to act ecologically. This way, they will have "more resources (time, money, [and] energy) to care about bigger, less personal social and proenvironmental issues" [31] (p. 244). It is precisely these resources, time, money, and energy, which are relevant to the question of whether shorter working weeks can result in more pro-environmental behaviour. Furthermore, considering that our society needs people to consume more sustainably, the strong competitive objectives of society, which inhibit pro-environmental action, need to be addressed first.

Much research has focused on the "value-action gap" or "knowledge-action gap" in sustainable consumption, which refers to the gap between individual consumers' values and attitudes towards pro-environmental behaviour [33]. Warde [34], however, stated that "values do not instigate behaviour" (p. 197). Instead, habits and habituation structure everyday practices that are supported by routines. Whereas policy approaches, such as Thaler and Sunstein's [9] "nudge theory", see the individual as the root of the problem, and the solution, a practice-theoretical approach frames the concept of "practice" as the object of analysis: practices produce "individuals and their values, knowledge, and capabilities, and not the other way around" [35] (p. 815). In this view, individuals are carriers of practice, who routinely perform actions "in accordance with shared understandings of normality" [36] (pp. 116-117). Through the performance, or the "doing", of the practices, the practices themselves are reproduced, modified, and changed. Consumption is, therefore, a moment in almost every practice, and consumer wants and desires thus emerge from these practices [37]. In this view, if our daily habits and routines structure our consumer habits, a sudden and drastic change in these routines could potentially change how we consume [6].

\subsection{The Potential for Work Time Reduction Policies}

Bocken and Short [38] argued that sustainable consumption's long-term goal must be: "societal aspirations that are fair for everyone; business models that add human value without taking away environmental value; and an economy which is stable and yet sus- 
tainable" [38] (p. 42). The literature demonstrates the potential of work time reduction policies to benefit all three pillars of sustainability simultaneously: society, the environment, and the economy. This study mainly focused on the social and environmental benefits of work time reduction; the economic benefits were beyond the scope of this paper. Concerning the social pillar of sustainability, both Hill et al. [39] and Zuzanek [40] addressed the problem of time pressure on well-being; research shows that flexibility in the timing and location of work can positively affect the balance between work and family [39,40]. Southerton's [1] research on "harriedness" explored how people relate to the problem of the "time squeeze", and explained it as one of the "allocating practices" to create more time for social interaction with family, friends, or work colleagues [1] (p. 22). An overspill within one sectioned-off time frame, e.g., work, can therefore result in less time for others, family, or the "self" [1]. Thus, perceived flexibility in the working week, rather than an absolute reduction in working hours, could balance work and non-work-related activities. Moreover, Speth et al. [41] indicated how working time reductions could benefit our wellbeing even if this corresponds to a lower income. Shorter work times or increased work flexibility could create more time for unstructured activities, such as exercise, volunteering, creative activities, and community engagement, which positively benefit subjective well-being and the environment [23].

The literature demonstrates how a combination of shorter working hours and 'perceived' flexibility in how and when we work can significantly benefit our well-being, the balance between work and family, and the environment. However, an area that requires more research is in its effect on the balance between work and the individual. From here on, this balance is referred to as the balance between work and "self". The impact of work on interests outside of the work and family domains requires further research; therefore, this paper aimed to address this gap in the literature. Furthermore, this study aimed to demonstrate the potential benefits of increased leisure time on pro-environmental consumption behaviour.

\section{Methodology}

\subsection{Research Design}

For narrative inquiry, face-to-face interviews were preferred, considering that this interviewing method allows for more in-depth data collection and a more comprehensive understanding [42]. Participants are more willing to engage in a more extended interview if they are conducted face-to-face since they will have a greater commitment to participate [42]. However, due to the contingencies of the COVID-19 restrictions, interviews were conducted via the digital platform Zoom. Zoom was expected to allow for a more comfortable and relaxed interaction than a phone interview would, especially when questions touched upon sensitive topics. Interviews varied in length between 40 to $60 \mathrm{~min}$ and, with consent from all participants, were recorded and then transcribed verbatim. Before the start of the interview, all participants were informed of the research topic and objectives, after which participants were asked for verbal consent to record and use the interview for research purposes.

Most interviews were in English since this was the first language of most, but not all, participants. Those whose first language was not English but had sufficient spoken command also did their interview in English; native Dutch participants were interviewed in Dutch. Where possible, participants were interviewed in their first language to aid the fluidity of the narration.

For this study, an ask-and-answer format of a conventional semi-structured interview would not have created the required depth of inquiry. On the other hand, a completely unstructured format lacked the direction the interviews needed and raised the vital issue of reliability: to what extent "do [the] respondents' answers to [the] prepared questions actually reflect their own experiences?" [43]. Therefore, a more fluid form of interviewing would enhance this research's reliability since the interviews aimed to capture the subjective experience of work and time during the lockdown. 
Anderson and Kirkpatrick [44] stated that "[n]arratives may come closer to representing the context and integrity of people's lives than more quantitative means of research" (p. 631). However, most participants needed some degree of structure to keep the interviews going in the right direction. Interviews were therefore structured around the themes of work and time, and questions were asked sparingly to avoid influencing participants' narratives, but appropriately, to steer the attention away from fears surrounding the virus and towards the topics being researched. Thus, a narrative, semi-structured interviewing approach provided participants with a structure, while still providing the freedom to elaborate. Questions were prepared before the interview, but were only used when needed; some participants required more steering, whereas others were comfortable narrating their individual experiences without much guidance. This method encouraged storytelling, without leading it to avoid an interviewer's bias, to gain "authentic, participant-driven narratives of personal experience" [45] (p. 2).

Another reason why the framework of a structured interview was not preferred is because interview questions "are meant to be used consistently during each interview to ensure neutrality and validity" [45] (p. 3). Since storytelling was greatly encouraged, a structured interview would only interrupt participants and also imply that questions had to be answered clearly and concisely. As a consequence, participants would not feel invited to respond to questions in a more narrative and reflective manner. Therefore, participants were stimulated to expand on their answers by giving verbal or non-verbal feedback. This approach also worked best with the digital platform used for the interviews.

Lastly, this style of interviewing, blending elements from the more standard semistructured interview and narrative inquiry, gives participants "time to reflect and examine the transformative aspects of their narratives, while still focusing on their experiences within a single phenomenon of interest" [45] (p. 5). This "funnelled approach" gives the interviewees a structure around which to build their own experiences, and therefore the interaction between researcher and participants is not usually required [45].

\subsection{Data Collection and Analysis}

This study recruited a total of 10 participants. The decision to conduct 10 narrative interviews for the research was informed by the handbook of Creswell [46], which suggested a minimum of two to three participants for narrative inquiry. Narrative inquiry does not have strict rules concerning the number of participants, as interviews aim to capture the individual experience which might give valuable, unexpected information [47]. Narrative inquiry does not aim to "capture truth", and it, therefore, does not aim to be generalisable. Rather, the "narratives discussed provide an avenue for further exploration" [48] (p. 127).

Chertkovskaya et al. [49] argued that "the present [COVID-19 crisis] constitutes a crucial moment for critical reflection and raises a series of urgent questions: what is our relationship with the family, community, environment and the state?" (p. 2). This research, therefore, aimed to capture the individual experience of leisure time and work during this global phenomenon in an attempt to critically reflect on what this might mean for a future, post-pandemic society. The research was conducted between June and August 2020, during, and right after, the height of the COVID-19 pandemic. Participants were either based in the United Kingdom (UK) or the Netherlands. Participants were recruited in these two countries for a specific reason: in these two countries, participants enjoyed a certain amount of freedom, in comparison to other EU countries, to go out for shopping, fresh air, or exercise. Moreover, participants located in the Netherlands continued to enjoy the freedom to meet with others while, in contrast, those in the UK followed much stricter rules during the official period of lockdown. Recruitment was solely performed through digital means and word of mouth.

The selection took place by "convenience sampling", and all participants were recruited based on specific criteria. Firstly, participants were either "furloughed" or working from home during the COVID-19 lockdown. "Furlough" is a term exclusively used in 
the UK; however, the Dutch government adopted a similar scheme in the Netherlands. In the UK, the furlough scheme guaranteed furloughed employees up to $80 \%$ of their usual income, whereas the Dutch government scheme covered $90 \%$ of people's pre-COVID salary $[50,51]$. All participants, therefore, continued to receive an income during the COVID-19 lockdown.

This study purposely recruited participants on these financial grounds; without a furlough scheme or continuous income from working from home, results would likely have been vastly different due to the added element of financial stress. Stress influences how we experience our leisure time [52]. Secondly, the study participants were either child-less or no longer financially or emotionally responsible for children. Previous research has focused on how long working hours affect the balance between paid work and family, but little research has focused on its effect on the balance between work and the "self" [39,53,54]. Here, the balance between work and "self" concerns any activities that do not exist within the domain of either family or work. Shove et al. [55] stated that "changing patterns of [paid] work and leisure imply a restructuring of a person's daily routines, from leisure and childcare through to cooking and time spent with friends and relatives, as time is necessarily reallocated between activities" (as cited in [23] (p. 12)). In connection to Shove et al. [55], this study aimed to research how participants spent their leisure time during the COVID19 lockdown without such childcare duties or many opportunities to spend "time with friends and relatives". Moreover, by omitting family and "childcare duties", fewer gender differences were expected to arise in how participants spent non-working hours during the lockdown; research still showed a disproportional gender division for unpaid household labour [56].

After transcription, pseudonyms were given to each participant to maintain anonymity. All transcripts, adding up to almost 40,000 words, were then organised and coded within the qualitative research software NVivo12. This research adopted a theoretical thematic analysis approach as a method "for identifying, analysing and reporting patterns [of meaning] within data" [57] (p. 79). The analysis was driven by the theoretical interest in the area rather than the data itself; this provided a detailed analysis of specific aspects of the data which is of interest to the research question [57]. The analysis procedure involved listening, close reading, reflecting upon the transcripts, and identifying themes within each interview. Initial labels were grouped, categorised, and/or merged using axial coding. These groups of data were then organised under bigger, over-arching themes that arose from the analyses of the interviews and represented meaning across the data. Important to note is that a theme, or code, is not dependent on prevalence, which is a quantifiable measure, but rather "whether it captures something important in relation to the overall research question" [57] (p. 82). A "good code" captures "the qualitative richness of the phenomenon" which is being studied; in this case, the COVID-19 lockdown ([58] (p. 1) quoted in [59] (p. 83)).

Even though the systematic process described above is presented as linear, the thematic research analysis is, in fact, iterative and reflective [59]. After the initial coding stage, further reflection on the transcripts led to a richer and more intricate web of themes and codes, and an overview of the richness of the data. There is too little space to explore all the ways the gathered data demonstrates overlap in themes between all ten interviews; therefore, this paper focused on the most prominent themes and sub-themes that arose out of the analysis.

Interviews were structured around two overarching themes: work and time. Within these two themes, various sub-themes arose. The sub-themes discussed in this section of the paper were the most prominent codes that emerged from the data. For ease of discussion, the analysis that follows separates codes into sub-themes within the two overarching themes mentioned above, work and time, while recognising the significant overlap and interconnection within and between these themes. 


\subsection{Rigour of the Research}

Firstly, while we can expect there to be differences in class or race and differences in sexual or gender identities among participants, this paper made no comparisons on these grounds at this stage. Instead, this study focused on the broader themes that have come out of the data and across all participants.

Secondly, this study recognised the possible implications of conducting the interviews via the digital platform of Zoom, which may have been less comfortable for some participants than others. The individual level of discomfort could have affected the flow of the conversation and influenced the responses to the interview questions. For example, one participant reflected on how their job pre-COVID-19 was making them quite unhappy. They remained somewhat reluctant to expand on this topic, which could have been due to the sensitivity of the issue or the interview style. Furthermore, Zoom did not facilitate eye contact, which can help to establish a more trustworthy environment [39]. Most participants, however, relaxed as the interview went on, which is reflected in the length of the answers given to later questions. Whereas the initial questions may have been answered quickly, participants were more relaxed and comfortable narrating their experiences later on.

Thirdly, interviews were audio-recorded but not video-recorded. Possible non-verbal communication was interpreted at the interview stage, but not part of the analysis. Following Paddock [48], the focus within this research was on capturing the subjective experience of time and work during the COVID-19 pandemic, which was most often reflected through unstructured and uninterrupted narration. The interviews were conducted with both native and non-native speakers, and analysis, therefore, did not focus on language use. The focus was on what was being narrated rather than how the stories were told. The analysis focused on the "semantics of narrated 'experience', and not the syntax of 'storied events'" [48] (p. 126).

As Anderson and Kirkpatrick [44] stated, "narrative research like all qualitative research does not set out to be generalizable and may only involve a small set of interviews" [44] (p. 633). The findings in this study can, therefore, not be generalised, but they merely provide a direction for further exploration.

To promote internal validity in the research, interviews were recorded and transcribed before connections between the different concepts were made. The themes and codes which arose from the data can be connected to the literature, which contributes to the validity of the research.

\section{Results and Discussion}

Out of all participants, six participants were furloughed, and four were working from home during the COVID-19 lockdown. Participants were located in either the UK or the Netherlands, which slightly altered what each situation looked like financially; furloughed participants continued to receive a minimum of $80 \%$ of their monthly income, or a minimum of $80 \%$ of their average income over the last three months. Participants who continued to work from home were receiving their usual salary; the impact of sudden financial stress could have negatively influenced the experience of leisure time during the COVID-19 lockdown. This paper recognised that participants would have experienced varying degrees of stress for different reasons during the lockdown, as this was not a controlled environment. A detailed overview of the study participants is provided in Appendix A.

Some participants of the study had part-time work while others worked full-time. This research aimed to capture the subjective experience of the balance between work and "self", regardless of how many hours participants were involved in paid employment. Moreover, an absolute number of paid working hours does not tell us anything about how many hours of unpaid work people do, for example, in the form of housework or care for others [56]. Therefore, this study aimed to explore how flexibility and autonomy in 
structuring paid work could increase subjective well-being, improve the balance between work and the "self", and, lastly, lower material consumer aspirations.

As stated earlier, while we can expect there to be differences between the participants based on age, gender, class, which may affect how people spend their time, this paper did not consider these differences at this stage.

\subsection{Work}

Within the theme of work, the discussion focuses on two aspects of work: why people work, and what participants gained with relevance to the balance between work and life during the COVID-19 lockdown. This research aimed to explore what participants value about their job and work in general, and which physical, psychological, and social benefits they may have experienced during the COVID-19 lockdown. Furthermore, how do these physical, psychological, and social benefits change the balance between work and the "self"?

\subsubsection{Why We Work \\ Connection and Belonging}

Throughout the interviews, most participants reflected on the social connections they gain through work, and some participants shared how work can confirm what we are good at. Furthermore, a job has the potential to create feelings of belonging, which make us feel needed and our work significant [60]. On the other hand, if work has this critical social function, it can also create the opposite; feelings of not fitting in can hurt both our work productivity, and our experience of both work and leisure time [60].

David (25) was one of the participants who had been furloughed since the start of the first lockdown in the UK and usually worked a 9-to-5 job as a mechanical workshop technician. David's situation demonstrated how an unpleasant work environment, which he referred to as both "mentally draining" and "challenging", can harm how we use our free time, and our relationships:

Being at home has sort of made me realise that you know, there is more to life than going to and from work, and then coming home from work you are tired, and you're not doing much on weekends. It's mentally draining. It is quite sad when I get a day off, when me and my partner are both off and, I do not really want to do anything because I'm very tired, and it causes a lot of strain on our relationship. - David, 25.

Nina (29) had been working from home since March when the marketing company had to close its office in Bristol. She shares how she enjoyed her job even though it was "quite stressful". Her job gave her autonomy over her work projects, and she enjoyed the responsibility in completing a project and the creativity that was part of the process:

I like to see an idea, a creative idea, develop. To start a project from the beginning and see it become reality. I like to have control over the project. And I'm good at what I do. - Nina, 29.

This quote demonstrates that Nina enjoyed being good at what she does. Still, she also enjoyed having control and a certain level of autonomy over the process, which is also an element of intrinsic motivation. Intrinsic motivation is directly linked to "positively valued experiences", more so than extrinsic motivation is [60] (p. 77). The importance of autonomy is further discussed in Section 4.1.2.

Similarly to Nina, India (26), who was furloughed from her part-time bar job, enjoyed the responsibility she gained through her work. She took pride in not only managing the bar by herself but also in giving people a good time:

It's nice to make people feel comfortable, [ ... ] being able to give them a nice experience, even though it is only a tiny part of their day. So I like that. Then [ . . ] we work on our own usually, which is a big responsibility. It's a nice challenge and achievement because the work itself is [ ... ] not necessarily challenging. - India, 26. 
India's narrative shows how "being able to give [people] a nice experience" gave her a feeling of achievement. This approach demonstrates intrinsic motivation, as she enjoyed providing customers with a friendly environment without the promise of extra rewards. This aspect of her job gave her satisfaction, especially since the job itself was "not necessarily challenging". Both India and Nina explained how responsibility and autonomy in their jobs provided a challenging environment, which ultimately fed into intrinsic motivation and led to job satisfaction [61]. Furthermore, most participants of the study frequently discussed various aspects of work demonstrating elements of intrinsic motivation. Examples of external motivation were frequent in the narrations.

Fundamental to work satisfaction is the social aspect; most participants talked about colleagues and social interactions in response to what they missed most about work prelockdown. Especially participants who continued to work from home missed the social aspect of work. Like Nina, Martha (59) had been working from home since the start of the first lockdown in the Netherlands. For Martha, the change to working from home had no practical disadvantages. However, it did have social implications; there was less connection within the team, and less pleasure working together when all communication happened through digital means.

Furthermore, when working from the office is optional, navigating schedules can be tricky and time-consuming. For Martha, working from home full-time, therefore, negatively affected her level of work satisfaction. Worth noting, however, is that Martha usually had a busy and rewarding social life. Without the social-distancing restrictions of the COVID-19 pandemic, there would be more opportunities for socialisation and a healthier work and life balance.

\section{Structure and Routine}

Work provides structure and routine to our daily lives. Most people spend a certain amount of time on paid work, which creates a structure around which we organise our leisure time and social events. The COVID-19 crisis changed people's patterns of work and leisure, which implied "a restructuring of a person's daily routine" [23] (p. 12). Some participants struggled more with these changes than others.

Ella (28) shared how she experienced pressure during the lockdown to spend her increased leisure time "wisely". Ella is a full-time assistant manager for a furniture shop in central Bristol, and she shares an apartment with her partner, David. To the question of what she missed most about work, she responded:

I think I miss the most a routine. Because obviously when I am at home it is very easy to fall back into a [ ... ] very lazy, waking up quite late, going to bed quite late again, so I did miss a routine sometimes of a way to fill my days. I would enjoy having a routine a bit more and waking up and having a purpose of my day, but I did enjoy having autonomy over that routine, and over the structure of my day. - Ella, 28.

Here, Ella shared how a routine led to the feeling of "purpose" in her day, but she also stated that while she missed having a routine, she enjoyed increased time autonomy. Furthermore, she described how routine links to the feeling of "purpose"; a routine divides the day into blocks of time and made her feel more "productive" and "purposeful". Eleonora (31) was furloughed from her job as a commis in a restaurant in central Bristol. On the one hand, she appreciated having a slower, more mindful, and less hasty routine, and a more predictable structure to her week during the lockdown. On the other hand, all her life, she has felt that "when [she works], [she is] productive".

For many participants, a routine seemed a requirement for a "productive" and "meaningful" day since time was considered as something that should not be "wasted but utilised" [1] (p. 12). India shared how going back to work straight after the first lockdown in the Netherlands ended made her realise how "healthy it is to keep busy with something, and have a routine, [to be] productive in that sense". Repetitive thoughts of needing to be "productive", seen in most participants' interviews, could cause distress throughout their days. 
Moreover, judging from the interviews, productivity is perceived in connection to work rather than leisure time. The topic of "productivity" is discussed in-depth in Section 4.2.1.

\subsubsection{Work and the Lockdown}

\section{Autonomy}

This section explores what participants gained during the first lockdown with relevance to work and the balance between work and self. A topic that recurred throughout all interviews was "autonomy", i.e., autonomy of time spent working and time spent not working and of the balance between the two. Both furloughed participants and those working from home shared how the balance between work and life increased. Participants who were working from home shared how increased flexibility in working times gave them more leisure time without working fewer hours. Most had not just gained time after work, but also during the day. Nina shared that, since working from home, she started to take off an hour or two every afternoon to get outside, go on a hike, or do some yoga. She also shared how she appreciated being able to decide to work more on busy days, and less on days when she was "waiting around" for other colleagues. Regarding what she will miss most about working from home, she said:

I will miss my daily freedom. Because I am the owner of my time now. I can now decide when I work a long day, 7 or $8 \mathrm{~h}$, technically, or when I only work a half-day for example. So it's my own responsibility. Working from home, I am able to do those things and benefit from them. Because it's good for me to take a break from the screen, get fresh air, or do exercise and then get back to work. [... ] it helps me focus. - Nina, 29.

Nina touched upon the critical connection of work and health, both physical and mental; the ability to structure our own time, and precisely the time we work, allows us to take breaks more often. Research demonstrates the benefit of frequent short breaks on employee well-being, productivity, and health, which in turn leads to lower health care costs $[62,63]$.

As discussed earlier, Ella was looking forward to going back to a more structured work routine; however, she did "enjoy having authority over this new routine, and over the structure of [her] day".

I appreciated the possibility to take time to do things, as opposed to rushing. When I

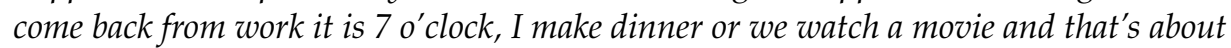
it because I don't really want to do anything else. I realised I can do so much more with my time when I have a full day [rather than just evenings] off. - Ella, 28.

For the past year, Martha was working four days from the office, and one day from home, which made her the only participant who had previously experienced the benefits of flexibility and autonomy over her work routine. Regarding her pre-COVID-19 lockdown working routine, she shared the following:

One day a week I don't have to rush, I do not have to commute [which is usually $40 \mathrm{~min}$ one wayl, I can also start later and work until later. So it is much more flexible. Also, I can easily do something in the home that needs doing, which before had to wait until the weekend. - Martha, 59.

Working from home one day a week gave Martha flexibility in the organisation of her schedule. This flexibility decreased stress and gave her the feeling of "having a lot more time" compared to working a usual nine-to-five from the office, which demonstrates the potential benefit of "perceived" extra leisure time due to increased flexibility, rather than an absolute increase in leisure hours. Martha did not feel strongly about wanting to further change her working pattern, unlike participants who did not have any flexibility in their location of work or working schedule. A study by Ryan et al. [64] stated that people experience an increased feeling of well-being at weekends; this is not because of disliking their job, but due to an increased sense of autonomy of the unforced activities they engage in during non-working hours. The next section further discusses the need for such "unforced leisure 
activities" for both personal well-being and increased productivity. Furthermore, a change in how we spend our leisure time could benefit environmental sustainability.

\subsection{Time}

Southerton [1] stated that both work and consumption are practices for which we allocate a certain amount of time; if either of these practices takes more time than allocated for, less will be available for others. Most often, our leisure time and time spent connecting with others have to make way for increased working hours [1]. The first COVID-19 lockdown created an increase in leisure time for the participants of this study. The interviews reflected the subjective experience of time during the lockdown, and this section, therefore, explores how participants spent this time, given the fact that opportunities for consumer activities and social interaction were limited.

\subsection{1. "Wasting Time": On Productivity}

Throughout the interviews, the topics of "usefulness" and "productivity" recurred. Surprisingly, these topics were predominantly discussed by furloughed participants and not those working from home. Without work, most furloughed participants struggled with feelings of stress over how to spend this leisure time in a "productive" way. According to a study by Sonnentag et al. [65], workers must have the ability to "switch off" mentally, to detach psychologically during non-work hours, as it allows them to be "more productive, engaged on the job, and convivial with colleagues" (p. 273). Therefore, a more flexible or shorter working week, which allows us to create more "unproductive, non-work moments", can instead make us more productive. Furthermore, it can make us more sociable colleagues [56]. This section discusses the participants' experience of "productivity" during the lockdown, and how the pressure of "productivity" can negatively influence the experience of leisure time.

Ella experienced the pressure of having to "make something out of the day" for it not to be a "waste". A good day during the lockdown was a productive day, and on bad days, negative thoughts about "unproductivity" would dominate. For Ella, a lack of structure and routine, usually provided by her job around which she structured her social and personal activities, felt overwhelming [23]. Some days she felt optimistic, active, and motivated. On these days, she engaged in activities such as baking and reading, and savoured quality time with her partner. Other days presented a vicious cycle; the pressure of having to use time "wisely" was overwhelming, which then resulted in an "unproductive" day with "so much nothingness". Eleonora shared a similar feeling of pressure to fill time as "too much free time is something [she did not] know how to handle". She explained how work keeps "her mind busy" and distracted. This discussion suggests that we are so used to structure our lives around work that it forms part of our identity; we may not know what to do or who we are without it.

The interviews reflected how most participants experienced pressures of "productivity" during the lockdown. Moreover, pressures of "productivity" arose when participants compared themselves to those around them. For example, some participants believed they were "wasting" time because friends or family started an online course or decided to learn a new language, and they did not. Pressures of "productivity" can be linked back to Veblen's idea of conspicuous consumption: a capitalist society puts so much value on leisure time, since it is so limited, that only those with an abundance of it can justify "wasting" it [7]. Before the COVID-19 pandemic, India had started a master's program in art history hoping it would "feed into her creativity", but decided to drop out when the program did not live up to its expectations:

I think it was really enlightening to question what productivity means and how all of us, engaging in society, Western society, have just been programmed to see life as this, from $A$ to $B$, from doing to doing, and from learning to learning, and we measure ourselves by what we achieve [ ... ] but we are also something without doing all those things, without a job or without another degree, or without a promotion. - India, 26. 
According to India, productivity is part of today's society; it tells us to measure our self-worth based on our achievements and our productivity. Moreover, India implied that productivity leads to more, i.e., wanting more, learning more, and doing more. Moreover, if the emphasis is on more, we can never be content with where we are at a certain point in time. This idea suggests that if we do not aim for more, and extrinsic rather than intrinsic goals, we are not productive members of society [66]. Giacomo (30), a part-time employee at a Bristol-based restaurant, shared India's opinion: he stated that "we are used to filling our time with work and being busy and useful". With too much time on our hands, we worry about how to spend it. However, Giacomo believed that the lockdown has given people the realisation that "we don't need to work so much, and we don't need so much money":

Because we couldn't spend so much [money] over the past few months, not on restaurants, going out to bars, but I have found out from talking to friends, that that's not what we missed the most. So we can do with less money, and we can do with less work. - Giacomo, 30.

Jack (27), a part-time student and part-time research intern, was also of the opinion that productivity and busyness are societal issues:

I think it could teach people something, lockdown, that we always feel we have to be productive. Work more, work harder, and it's never enough. Because someone else always works harder than us and always has more than us. And that's what we aspire to. - Jack, 27.

Productivity often feeds into the need to be busy, which has become the "main source of a full and valued life" [1] (p. 6). However, research shows no link between higher working hours and productivity; in fact, Nyland [67] argued that a reduction in working hours has "a strong positive association with higher [labour] productivity" ([67] quoted in [68] (p. 76)). India also believed that people "cannot help but compare [themselves] to others"; the comparison is inherent to vertical aspiration [11] (pp. 5-6).

Both India's and Jack's observations can be linked to research by Kasser [66] and Kasser and Sheldon [61]. They stated that the idea that material affluence brings happiness is "fundamental to the ideology of capitalistic, consumer-based economies" (p. 243). As discussed earlier in this study, in a capitalist society, increased productivity leads to higher wages rather than more leisure time which creates a "cycle of work and spend" [11] (p. 9). However, research also shows a link between consumer aspirations and lower personal well-being. If these materialistic aspirations lead to lower levels of well-being, should we be celebrating competition, productivity, and wealth in society [62]? Moreover, given the fact that current and predicted patterns of consumption are not sustainable, this materialistic "cycle of work and spend" should be reformed if we are serious about creating sustainable development [62] (p. 243).

\subsubsection{Time for Social Connection}

All participants agreed on one main thing: they struggled most with restrictions on social interaction and engagements. Those living with partners and/or friends were able to spend more time with each other, whereas those residing alone shared that they struggled with social isolation from time to time. Participants located in the Netherlands continued to enjoy the freedom to meet with others, as long as social distancing rules were strictly adhered to. In contrast, those in the UK followed much stricter rules during the official period of lockdown. The level of enjoyment during the lockdown and struggle with social restrictions could, therefore, have been influenced by these geographical differences.

Overall, most participants agreed that without the stress from work and everyday life, there was more time and "space" for connection that did not revolve around going out and spending time and money in bars, restaurants, or clubs. Instead, several participants stated that the level of connection increased:

Actually, being in lockdown, a lot of people have sort of acknowledged the distance we have from each other, so I've been able to talk to my parents, my brother, and some other 
friends a lot more, albeit not face to face but I have much more meaningful conversations with people. And I feel that my friendships have done a lot better from it. - David, 25.

According to David, the lockdown has provided time for reflection on "what you do to enjoy yourself, and whether you actually find that enjoyable". Social appointments often revolve around "going out", i.e., spending time and money with people outside of the domestic realm. Instead, David found it beneficial "to have meaningful time with people, rather than having to go out of our way to do something". For him, and most participants, social interaction was more meaningful, intimate, and enjoyable without the pressure to "do something", i.e., going out and spending money.

India shared how she was not only more connected to friends and family, but that she also observed more connection between strangers on the street in Amsterdam:

Firstly, people were more open to one another. So I kind of felt this "togetherness". It was easier to make a connection with someone. There was more eye contact when you walked past someone in the street. It felt like we really valued this connection with each other. - India, 26.

India found it easier to have social interaction with people, even with those she did not know well. Moreover, her word choice is noteworthy; during this period of lockdown, a meaningful connection was considered something incredibly "valuable". Other participants witnessed this connection between strangers and neighbours as well, which inspired altruistic actions:

I have friends that are a bit closer to the neighbours, they have got to know their neighbours, and helped each other out sometimes. Practically but also, maybe some people around have been living by themselves and they may really benefit from a simple daily chat. - Sofia, 28.

According to Sofia, an increase in non-working hours made people more observant of what is going on around them and what other people may be experiencing on a personal level. She implied that when we are busy and focused on our personal struggles, we become less perceptive of these signs. Giacomo shared this opinion, as he stated that one of the things he enjoyed most during the quarantine was the ability to support others as they were struggling:

Maybe at the beginning, I was a bit lost as well, for sure, but as soon as I felt better I wanted to help others because I benefitted from staying in touch with friends, and talking to friends so I wanted to offer the same. 'We're in this together, it's not so bad, and we can do this!' - Giacomo, 30.

Most participants also shared how they found the lockdown significantly less challenging knowing that everyone was going through it together. As India said, there was a sense of "togetherness" in going through a global pandemic together and, without connections found through work, participants aimed to find these connections elsewhere.

Earlier on in this study, participants shared how work provides a vital opportunity for social interaction and connection. Surprisingly, furloughed participants shared how social limitations during the lockdown had, in fact, increased the level of connection between people. Social interactions became more "meaningful" when participants were not stressed out by work or meeting to spend time and money outside of the house. Moreover, the responsibility of work made space for the commitment and pleasure of taking care of each other. It can, therefore, be suggested that, among study participants, material aspirations made space for more altruistic behaviour. A global lockdown with fewer to no opportunities for consumer activities forced people to re-assess what is important, which brought people and communities closer together $[7,23]$.

\subsubsection{Time-Consuming Activities}

According to Schor [11], "television watching is positively correlated with consumer expenditures and negatively correlated with savings" [11] (p. 7). As working hours in- 
creased, watching television became the default activity, which led to a rise in materialistic, consumer aspirations and, as discussed earlier in this paper, a decline in well-being [11]. Participants shared how they were usually not able to save much money and that saving money was not a priority, but most were able to save more during the lockdown. Furthermore, even though most participants gained (significantly) more leisure time, their interviews also showed a wider variety of activities on which to spend leisure time.

During the lockdown, both Ella and her partner were furloughed, but pre-lockdown they did not get to spend much time together and, instead, they would usually spend most evenings after work in front of the TV. Ella suggested that she watched a lot less TV during the lockdown. Earlier, David shared how more leisure time and less work-related stress greatly benefited the relationship with his partner, and many of his other personal relationships. More leisure time made both Ella and David excited about the different ways to spend it, and it benefited their well-being and their relationship. Both shared how they would appreciate the opportunity for more leisure time to spend together, rather than just evenings watching TV.

Participants who lived with friends, family, or a partner spent more quality time together during lockdown compared with pre-COVID-19. Moreover, as discussed earlier, the pressure to spend time "wisely" and "productively" could negatively affect the day, but it could also stimulate participants to focus on what they found important. Furthermore, the interviews demonstrated how a limitation in choices for consumption and spending time inspired many participants creatively. For example, some participants started baking bread and cakes and, overall, most found fulfilment in doing more with less. Having less stimulates our creativity and, as a consequence, it increases our sense of well-being [66]. To illustrate, Giacomo bought a piano right before lockdown to spend his time learning a new instrument, Sofia started painting, and Eleonora started knitting, which was a creative hobby she always wanted to try. Other participants spent time reading, writing, painting, drawing, or looking for new ways to spend time.

During the lockdown, Elena (28), who lives with housemates, gained some extra leisure time due to working from home, which was time she could not spend with friends or family. She, therefore, decided to look for alternate ways to spend her time because, as she said, "there is only so much Netflix you can watch". For Elena, who loves to cook, a perceived lack of time had always restricted her creatively:

I've always thought 'one day I'll try those things', but I never thought, or believed, I had time. But I discovered it really takes little effort sometimes to make homemade bread, or your own tomato sauce or all those little things. So before I would buy a lot of things out of convenience, and now I realise that it's really not that difficult. - Elena, 28.

Elena learned that making some of these things from scratch was not as difficult and time-consuming as she had thought; moreover, they saved her money. Longer working hours leave us "pressed for time", but a higher income allows us to outsource timeconsuming activities. We can pay someone to clean our house, pay restaurants to cook for us, and buy bread and sauces ready-made $[1,66]$. A voluntary downshift in exchange and a lower salary could therefore increase participation in DIY activities. For many participants, however, the acts of cooking and baking during lockdown were less about food or spending time, and more about the social action of sharing food with good company. Sofia (28), who was been furloughed from her job as a shop assistant, enjoyed similar activities during the lockdown:

I always wanted to bake more pizza and focaccia. I like making those things but they are time-consuming so I don't do it much, and I usually bake with quick yeast. And I love bread so I always buy it, but it is expensive. Now I have been experimenting with using a sourdough starter so that's been really fun. - Sofia, 28.

Like Elena, Sofia thought that baking bread the traditional way was a time-consuming and challenging process. However, during the lockdown, she enjoyed experimenting with sourdough to make a variety of bread products. Even though baking sourdough 
bread demands a more extended time commitment, and more effort, time is not all that matters; the creativity found in making something from scratch ourselves increases our well-being [66]. Moreover, Sofia shared how cooking from scratch made her more aware of how her choices impact the environment. With an increase in free time, while maintaining a similar income, she had been trying to shop more consciously. How more leisure time can lead to more conscious consumer behaviour is further discussed in the next section.

Moreover, there is value in the feeling of competence gained through self-reliance, e.g., growing our food, baking our bread, repairing our own bike, or repurposing something we no longer need. Self-reliance, being able to make things ourselves, thus also increases our well-being [66]. These activities discussed are also considered pro-environmental. How these types of activities could benefit environmental sustainability is addressed in the next section as well.

Many participants narrated what their days consisted of while highlighting "small pleasures", such as reading in the garden, cycling on a sunny day, or sharing a meal with others. India shared how an increase in free time made her enjoy moments in her routine she previously deemed "tedious" or "mundane":

During the quarantine, things like making a coffee in the morning were suddenly a big deal. And very warming. Very wholesome. And that kind of changes when you go back to [... ] life. Everything feels like a task, a chore, rather than something to enjoy. - India, 26.

India demonstrated her desire to maintain this appreciation for "small pleasures" when she goes back to work, and the hurriedness of everyday life picks up again [1]. Furthermore, she shared how appreciating small moments in her routine was "an exercise in stillness". Without the stress and distraction of everyday life, India found inspiration in the mundane and time to finish her book of poetry. Without the time offered by lockdown, she believed she would have never created time to achieve this goal: "I would have never taken myself so seriously".

A focus on small pleasures and "do-it-yourself" also meant that most participants changed their usual spending patterns during the lockdown. Lockdown gave India time to reflect on how she lives paycheck to paycheck. India learned the importance of financial independence and self-reliance for her subjective well-being. The next quote expresses how India considered the COVID-19 lockdown "a good lesson" and a confrontation with her patterns of spending and financial dependence:

I am broke, really, really broke, and I've had to depend on my father and partner to support me financially, and I really don't want that anymore. I realise what it means to be an adult and that I should be accountable for my spending patterns. So it has really changed my perception of money. And financial independence. - India, 26.

This section of the study demonstrated how the COVID-19 lockdown increased leisure time, which participants used to work towards personal goals and creative endeavours. Moreover, the lockdown created opportunities for time-consuming activities. These ways of spending time benefit subjective well-being, which in turn helps social relationships. Furthermore, how the participants spent and appreciated leisure time during the lockdown could change the future of work and inform sustainable consumption policies. A change in how we spend time can inspire a shift towards more sustainable consumption [23]. The next section further discusses how shorter or more flexible working week policies could change the "future of work" and, simultaneously, how it can stimulate more sustainable consumption.

\subsection{Future of Work}

This analysis focused on the most prominent themes and sub-themes to have emerged from all ten interviews. Multiple participants described the COVID-19 lockdown as a "lesson" for themselves and for society as a whole. Life is more than work, and a better balance between the two can have both personal and environmental benefits. 
This study demonstrated that most participants gained multiple benefits from increased leisure time: this was true for both those furloughed and those working from home. The lockdown led to an increase in leisure time to spend with family and partners, where possible, given the COVID-19 social distancing restrictions. Moreover, less work and work-related stress created more unstructured leisure time for (creative) hobbies and activities for self-development. Furthermore, and surprisingly, more leisure time and a restriction on how to spend it led to an appreciation for the "small pleasures" in everyday life. The appreciation of these small pleasures is reflective of a shift in the subjective value of leisure time.

Moreover, several furloughed participants shared they would choose more leisure time over a higher income, if given the option. Ella shared how the lockdown made her realise "how much she can really do with a whole day off", rather than just an evening. Similarly, both Giacomo and Sofia would also choose more leisure time over a higher income. These participants also shared how this sudden gain in leisure time was overwhelming at first, but, after the initial shock, a gift. Several participants used the increased leisure time to reflect on their personal goals, which may have not been a priority beforehand; India was able to work full-time on her book of poems, which was a personal goal for years. On the other hand, both Giacomo and David shared how the lockdown reaffirmed their need for a change of career. For these participants, an increase in leisure time highlighted the importance of joy, satisfaction, belonging, and autonomy in work for overall well-being and social relationships.

The findings of this study demonstrated how the lockdown made participants willing to "downshift", work less, and possibly earn a lower salary in exchange for more free time, since experiencing the personal benefits of more leisure time. As discussed earlier in this paper, the literature demonstrates how a voluntary reduction in working hours, which may or may not lower one's income, can change our consumption patterns [11,22,68]. The connection between leisure time and sustainable consumption is discussed next.

\subsection{Can an Increase in Leisure Time Foster more Sustainable Consumption?}

As discussed earlier in this paper, Kollmuss and Agyeman [31] stated that the question of what shapes pro-environmental behaviour is rather complex. The different ways in which a flexible working week might stimulate pro-environmental behaviour cannot be discussed at large in this study. This section, therefore, focuses on one aspect of consumer behaviour that is of interest to this study: pro-environmental behaviour can be either intentional or non-intentional. In other words, people can purposely make choices that are, in their eyes, the most pro-environmental choices, or they can make choices for other reasons, e.g., for stress-relief, physical health, or simply because they do not have the option to consume (e.g., because of a travel ban during lockdown). The activities are, therefore, often inherently but non-intentionally pro-environmental.

Sofia focused time and energy on adopting more sustainable consumer habits during the lockdown. She always tried to shop more sustainably, e.g., she considered "where products come from" or tried to "avoid plastic", but this was usually more difficult when she worked more and had less free time. Without access to a car, the shop where she could afford to buy her food was a 40-min walk away, but during the lockdown, she had time to walk there once a week. Moreover, as both Sofia and Kollmuss and Agyeman [31] stated, consumers need time, energy, and money to adopt more sustainable consumption practices into their routines. This statement suggests that more sustainable consumer behaviour can be stimulated by the creation of more time to first "[satisfy our] personal needs", after which consumers can focus on "social and pro-environmental issues" [31] (p. 244).

One primary way this paper demonstrated a change in consumption is through how participants spent their time during the lockdown. Sofia was the only participant to make a conscious and intentional choice to dedicate more free time to sustainable consumer activities; however, other participants also engaged in more "green" and "pro-environmental" consumer activities, albeit non-intentionally. Participants took more pleasure in "simple" 
activities, such as cooking, enjoying a cup of coffee in the morning, or a good conversation with a friend, therefore appreciating "small pleasures". Moreover, some activities, such as cooking and baking, could be engaged in for different reasons: for example, they could be a creative way of spending time, a way of showing appreciation, or an opportunity for connection by sharing food with others. This research recognised that participants may only have engaged in these activities since options on how to spend leisure time were limited. However, participants of the study experienced increased personal and social well-being, having spent time differently than usual, and having more leisure time to balance work and non-work obligations.

This study was limited in researching the effect of increased leisure time on intentional pro-environmental consumer behaviour since most opportunities for consumption disappeared during the COVID-19 lockdown. We can, therefore, not make any predictions about how participants will continue to consume in a post-pandemic world. As witnessed in several countries after lockdowns, governments have taken measures to return to "normal" (e.g., [49]). Unfortunately, such measures have also encouraged a return to business-as-usual to encourage economic revival, hence consumers initially demonstrate less sustainable behaviour due to a re-introduction of work and unsustainable activities such as international travel. Still, the interviews also showed how so-called "lessons" on the value of leisure time and the future of work may not be so easily unlearned. Future research should, therefore, focus more on how an increase in leisure time in a post-pandemic world changes intentional, sustainable behaviour.

\section{Conclusions}

This study researched the potential of a restructured working week, i.e., a shorter or a more flexible working schedule, to improve human well-being, the balance between work and the "self", and the environment simultaneously. This study addressed a gap in the literature: effects of leisure time on the balance between work and the "self". However, previous research has also demonstrated the benefits of work flexibility on the work-life and work-family balance. As stated earlier, the results did not aim to be generalisable. The interviews aimed to capture the individual experience, and they, therefore, provided an "avenue for further exploration" [48] (p. 127).

Firstly, the analysis of the interviews provided insight into the social function of work. Aside from the financial necessity, participants demonstrated their belief that work creates feelings of connection and belonging; however, it can also create the opposite, which can harm the experience of leisure time. Moreover, paid work provides our lives with structure and routine, which results in an increased feeling of productivity.

Secondly, this study explored how a change in the structure of work during the COVID-19 lockdown may benefit the balance between work and "self". What have we learned from this global pandemic with regards to the "future of work"? This research demonstrated how a restructuring of the workweek, for example, by working from home or working fewer hours, has the potential to change the individual experience and subjective value of leisure time.

Moreover, the COVID-19 lockdown created increased opportunities for autonomy which led to more unforced activities and hence benefited personal productivity. With more free time, or more flexibility and autonomy over the working schedule, participants recognised the benefit of more time for social connection, increased physical and psychological well-being, and improved balance between work and "self".

Furthermore, this study demonstrated that an increase in autonomy can be achieved through increased flexibility in the working week or a shorter week. Most participants of the study would choose shorter working hours and an increase of leisure time over a higher salary, especially when post-pandemic life allows for more freedom and more opportunities for how to spend leisure time, both together and alone.

Lastly, this study aimed to demonstrate whether more leisure time can change how we spend our free time. If we have more of it, are we more likely to spend it in pro- 
environmental ways? Moreover, can an increase in leisure time potentially challenge materialist objectives and thereby address the global problem of overconsumption? At the start of the lockdown, participants struggled with a negative pressure to use this increase in leisure time in a "productive" way, since "productivity" was usually seen with relevance to work and not leisure time. Among all participants, reduced pressures of "productivity" inspired an appreciation of "small pleasures" and increased appreciation of time for the "self", creativity, and time to spend towards personal goals.

Furthermore, this study suggested that an increase in leisure time can lead to both intentional and non-intentional pro-environmental behaviour; however, the setting of this research had limited opportunities for researching intentional, sustainable behaviour.

\section{Further Research}

Our study had its limitations, which leads to recommendations for further research. The study recruited participants based on two main criteria. Firstly, participants continued to receive an income during the first lockdown, either through the "furlough" scheme or by continuing to work from home. Secondly, the study participants were either child-less or no longer financially or emotionally responsible for children. Due to these specific recruitment criteria and the choice for "convenience sampling", the majority of participants were under the age of 30. Considering that generation $Y$ and $Z$ are believed to be "greener" than previous generations, further research with a broader age range could lead to different insights into the effect of leisure time on pro-environmental behaviour [69,70].

Moreover, while this research was limited on studying intentional sustainable consumption, it could be used to inform further research on how a shorter working week or more flexible working patterns might change unsustainable behaviour and foster intentional, sustainable consumer behaviour.

While the benefits of work cannot be denied, e.g., financial independence and opportunities for social interaction, an increase in leisure time was a positive experience for all participants. Here, we discussed both an increase of total hours of leisure and perceived increase due to flexible working patterns, which give more opportunity for breaks and, in turn, benefit subjective well-being, physical and mental health, and the balance between work and "self". Additionally, the literature suggests how a shorter working week, or a more flexible working week, and frequent short breaks dispersed throughout the working day increase productivity.

Moreover, this study argued for the necessity to implement opportunities to create more flexibility in the working week. Not everyone will be interested in a shorter working week with fewer hours and a lower salary. However, increased flexibility can benefit both employee and employer through increased employee health and well-being, both physical and psychological, and through a better balance between work and non-work, which would lower health care costs.

Further research should focus on the connection between leisure time and intentional, sustainable behaviour in a post-lockdown and post-pandemic setting. Options for consumption, both sustainable and unsustainable, were limited or non-existent during the lockdown, and this was therefore not something that could be thoroughly studied. This paper could, therefore, be used as a starting point for further research into the topic of pro-environmental consumption in a post-pandemic future.

Author Contributions: Conceptualisation, J.S.K.; methodology, J.S.K.; data curation, J.S.K.; data analysis, J.S.K.; writing — original draft, J.S.K.; writing—review and editing, W.L., J.S.K. All authors have read and agreed to the published version of the manuscript.

Funding: Article Processing Charge covered by the Open Access Fund of the Open Universiteit Library Committee.

Institutional Review Board Statement: The study was conducted according to the guidelines of the Declaration of Helsinki, however Institutional Review Board approval was not requested for this data collection. 
Informed Consent Statement: Informed consent was obtained from all subjects involved in the study.

Data Availability Statement: Due to the nature of this research, the participants of this study did not agree for their data to be shared publicly.

Acknowledgments: We are grateful to Jessica R. Paddock for her support and feedback throughout the research process. We would also like to thank our five anonymous reviewers for their constructive comments.

Conflicts of Interest: The authors declare no conflict of interest.

\section{Appendix A}

Table A1. Overview of Participants.

\begin{tabular}{|c|c|c|c|c|c|}
\hline Pseudonym & Age & Contract & Job & Furloughed & Working from Home \\
\hline David & 25 & Full-time & $\begin{array}{l}\text { Mechanical } \\
\text { Workshop Technician }\end{array}$ & $x$ & \\
\hline Elena & 28 & Full-time & $\begin{array}{l}\text { Administrator/customer } \\
\text { service employee at a } \\
\text { pension company }\end{array}$ & & $x$ \\
\hline Eleonora & 31 & Full-time & Commis waiter & $x$ & \\
\hline Ella & 28 & Full-time & $\begin{array}{l}\text { Assistant- manager in a } \\
\text { furniture shop }\end{array}$ & $x$ & \\
\hline Giacomo & 30 & Part-time & Chef/waiter in a restaurant & $x$ & \\
\hline India & 26 & Part-time & Bartender & $X$ & \\
\hline Jack & 27 & Part-time & Student/research intern & & $x$ \\
\hline Martha & 59 & Full-time & $\begin{array}{l}\text { Employee at a medical } \\
\text { non-profit organisation }\end{array}$ & & $x$ \\
\hline Nina & 28 & Full-time & $\begin{array}{l}\text { Employee at a } \\
\text { marketing compnay }\end{array}$ & & $x$ \\
\hline Sofia & 28 & Part-time & Shop assistant & $x$ & \\
\hline
\end{tabular}

\section{References}

1. Southerton, D. "Squeezing Time": Allocating practices, coordinating networks and scheduling society. Time Soc. 2003, 12, 5-25. [CrossRef]

2. Schippers, M.C. For the Greater Good? The Devastating Ripple Effects of the Covid-19 Crisis. Front. Psychol. 2020, 11, 577740. [CrossRef]

3. United Nations Development Programme. Human Development Report 2015: Work for Human Development; United Nations: New York, NY, USA, 2015. Available online: http://hdr.undp.org/sites/default/files/2015_human_development_report.pdf/ (accessed on 1 August 2020).

4. Kennedy, E.H.; Krahn, H.; Krogman, N.T. Downshifting: An Exploration of Motivations, Quality of Life, and Environmental Practices. Sociol. Forum 2013, 28, 764-783. [CrossRef]

5. Cockman, R.L.; Pyke, L. Downshifting: Boundary management for the privileged few? Ephemer. Theory Polit. Organ. 2020, 20, 43-70.

6. Jackson, T. Live Better by Consuming Less? Is There a "Double Dividend" in Sustainable Consumption? J. Ind. Ecol. 2005, 9, 19-36. [CrossRef]

7. Trigg, A.B. Veblen, Bourdieu, and Conspicuous Consumption. J. Econ. Issues 2001, 35, 99-115. [CrossRef]

8. Bharath, V.; Chamoli, D.; Kumar, R.; Shankar, R. The Effect of Busyness on Productivity of an Individual. Int. J. Indian Psychol. 2017, 4, 175-180.

9. Thaler, R.H.; Sunstein, C.R. Nudge: Improving Decisions about Health, Wealth and Happiness; Yale University Press: New Haven, CT, USA, 2008.

10. Douglas, M. Relative poverty, relative communication. In Traditions of Social Policy; Halsey, A., Ed.; Basil Blackwell: Oxford, UK, 1976.

11. Schor, J. Understanding the New Consumerism: Inequality, Emulation and the Erosion of Well-Being; PSW Papers; Faculteit Politieke en Sociale Wetenschappen, Universiteit Antwerpen: Antwerpen, Belgium, 2002. 
12. Borghesi, S. The Environmental Kuznets Curve: A Survey of the Literature. FEEM Working Paper, University of Siena, Department of Government, Law, Economics, Social Science Research Network. 1999. Available online: http:/ / papers.ssrn.com/ sol3 / papers.cfm?abstract_id=200556 (accessed on 1 August 2020).

13. Conrad, A.; Cassar, L. Decoupling Economic Growth and Environmental Degradation: Reviewing Progress to Date in the Small Island State of Malta. Sustainability 2014, 6, 6729-6750. [CrossRef]

14. Schnaiberg, A. The Environment: From Surplus to Scarcity; Oxford University Press: Oxford, UK, 1980.

15. Spaargaren, G.; Mol, A. Environmental Social Sciences and Sustainable Consumption. In Encyclopedia of Consumer Culture; Southerton, D., Ed.; Sage Publications: London, UK, 2011; pp. 538-545.

16. Muncy, J.A.; Vitell, S.J. Consumer ethics: An investigation of the ethical beliefs of the final consumer. J. Bus. Res. 1992, 24, 297-311. [CrossRef]

17. De Groot, J.I.M.; Steg, L. Mean or green: Which values can promote stable pro-environmental behavior? Conserv. Lett. 2009, 2, 61-66. [CrossRef]

18. Kumar, P.; Polonsky, M.J. An Analysis of the Green Consumer Domain within Sustainability Research: 1975 to 2014 . Aust. Mark. J. 2017, 25, 85-96. [CrossRef]

19. Leonidou, C.N.; Leonidou, L.C. Research into environmental marketing/management: A bibliographic analysis. Eur. J. Market. 2011, 45, 68-103. [CrossRef]

20. Leonidou, L.C.; Leonidou, C.N.; Kvasova, O. Antecedents and outcomes of consumer environmentally friendly attitudes and behaviour. J. Mark. Manag. 2010, 26, 1319-1344. [CrossRef]

21. Dietz, T.; Fitzgerald, A.; Shwom, R. Environmental values. Annu. Rev. Environ. Resour. 2005, 30, 335-372. [CrossRef]

22. Schor, J. The Triple Imperative: Global Ecology, Poverty and Worktime Reduction. Berkeley J. Sociol. 2001, 45, 2-16.

23. Pullinger, M. Working time reduction policy in a sustainable economy: Criteria and options for its design. Ecol. Econ. 2014, 103, 11-19. [CrossRef]

24. Elgin, D.; Mitchell, A. Voluntary Simplicity. The Co-Evolution Quarterly, 1 June 1977; 5-18.

25. Osikominu, J.; Bocken, N. A Voluntary Simplicity Lifestyle: Values, Adoption, Practices and Effects. Sustainability $2020,12,1903$. [CrossRef]

26. Drake, J. Downshifting: How to Work Less and Enjoy Life More; Berrett-Koehler: San Francisco, CA, USA, 2009.

27. Akenji, L. Consumer scapegoatism and limits to green consumerism. J. Clean. Prod. 2014, 63, 13-23. [CrossRef]

28. Laroche, M.; Bergeron, J.; Barbaro-Forleo, G. Targeting consumers who are willing to pay more for environmentally friendly products. J. Consum. Mark. 2001, 18, 503-520. [CrossRef]

29. Long, M.M.; Schiffman, L.G. Consumption values and relationships: Segmenting the market for frequency programs. J. Consum. Mark. 2000, 17, 214-232. [CrossRef]

30. Sharma, S.; Bagoria, H. Green marketing: A gimmick or the real deal. Int. J. Res. Financ. Market. 2012, 2, 406-414.

31. Kollmus, A.; Agyeman, J. Mind the Gap: Why Do People Act Environmentally and What are the Barriers to Pro-Environmental Behavior? Environ. Educ. Res. 2002, 8, 239-260. [CrossRef]

32. Steg, L.; Vlek, C. Encouraging pro-environmental behaviour: An integrative review and research agenda. J. Environ. Psychol. 2009, 29, 309-317. [CrossRef]

33. Young, W.; Hwang, K.; McDonald, S.; Oates, C.J. Sustainable consumption: Green consumer behaviour when purchasing products. Sustain. Dev. 2010, 18, 20-31. [CrossRef]

34. Warde, A. Consumption: A Sociological Analysis; Springer: Berlin/Heidelberg, Germany, 2016.

35. Spaargaren, G. Theories of practice: Agency, technology, and culture exploring the relevance of practice theories for the governance of sustainable consumption practices in the new world order. Glob. Environ. Chang. 2011, 21, 813-822. [CrossRef]

36. Evans, D.; McMeekin, A.; Southerton, D. Sustainable consumption, behaviour change policies and theories of practice. COLLeGIUM 2012, 12, 113-129.

37. Warde, A. Consumption and Theories of Practice. J. Consum. Pract. 2005, 5, 131-151. [CrossRef]

38. Bocken, N.; Short, S. Towards a sufficiency-driven business model: Experiences and opportunities. Environ. Innov. Soc. Transit. 2016, 18, 41-61. [CrossRef]

39. Hill, E.; Hawkins, A.; Ferris, M.; Weitzman, M. Finding an Extra Day a Week: The Positive Influence of Perceived Job Flexibility on Work and Family Life Balance. Fam. Relat. 2001, 50, 49-58. [CrossRef]

40. Zuzanek, J. What Happened to the Society of Leisure? Of the Gap between the "Haves" and "Have Nots" (Canadian Time Use and Well-being Trends). Soc. Indic. Res. 2015, 130, 27-38. [CrossRef]

41. Speth, J.G.; Costanza, R.; Hassol, S.J.; Kasser, T. Some Convenient Truths: Scaling Back Our Energy-Hungry Lifestyles Means More of What Matters, Not Less. Grist. 10 December 2007. Available online: http:/ / www.grist.org/article/scaling-back-ourenergy-hungry-lifestyles-means-more-of-what-matters-not-le/ (accessed on 17 August 2020).

42. Holbrook, A.; Green, M.; Krosnick, J. Telephone versus Face-to-Face Interviewing of National Probability Samples with Long Questionnaires: Comparisons of Respondent Satisficing and Social Desirability Response Bias. Public Opin. Q. 2003, 67, 79-125. [CrossRef]

43. Silverman, D. Doing Qualitative Research; Sage: London, UK, 2017.

44. Anderson, C.; Kirkpatrick, S. Narrative interviewing. Int. J. Clin. Pharm. 2016, 38, 631-634. [CrossRef] 
45. Mueller, A. Episodic Narrative Interview: Capturing Stories of Experience with a Methods Fusion. Int. J. Qual. Methods 2019, 18. [CrossRef]

46. Creswell, J.W. Qualitative Inquiry E Research Design: Choosing among Five Approaches, 3rd ed.; Sage: Thousand Oaks, CA, USA, 2013.

47. Sim, J.; Saunders, B.; Waterfield, J.; Kingstone, T. Can sample size in qualitative research be determined a priori? Int. J. Soc. Res. Methodol. 2018, 21, 619-634. [CrossRef]

48. Paddock, J. Household consumption and environmental change: Rethinking the policy problem through narratives of food practice. J. Consum. Cult. 2017, 17, 122-139. [CrossRef]

49. Chertkovskaya, E.; Alakavuklar, O.N.; Husted, E.; Rácz, M. Reconfiguring work and organizing for post-pandemic futures. Ephemer. Theory Polit. Organ. 2020, 20,1-18.

50. Bernal, N. The UK's Coronavirus Furlough Scheme, Explained by Experts. WIRED, 29 July 2020. Available online: https: / / www.wired.co.uk/article/uk-furlough-schemejobprotection/ (accessed on 1 October 2020).

51. Newmark, Z. Dutch Gov't to Cover 90\% of Salaries Lost for Work Hours Reduction: Report. NL Times, 17 March 2020. Available online: https://nltimes.nl/2020/03/17/dutchgovt-cover-90-salaries-lost-workhours-reduction-report/ (accessed on 20 July 2020).

52. Zuzanek, J. Work, leisure, time-pressure and stress. In Work and Leisure; Haworth, J.T., Veal, A.J., Eds.; Routledge: London, UK, 2004; pp. 123-144.

53. Hammer, L.B.; Allen, E.; Grigsby, T.D. Work-Family Conflict in Dual-Earner Couples: Within-Individual and Crossover Effects of Work and Family. J. Vocat. Behav. 1997, 50, 185-203. [CrossRef]

54. Baugh, S.G. Research in Careers; Information Age Publishing: Charlotte, NC, USA, 2016.

55. Shove, E.; Pantzar, M.; Watson, M. The Dynamics of Social Practice: Everyday Life and How It Changes; Sage: Los Angeles, CA, USA, 2012.

56. Stronge, W.; Harper, A.; Guizzo, D.; Lewis, K.; Ellis-Peterson, M.; Murray, N.; Hester, H.; Cole, M. The Shorter Working Week: A Radical and Pragmatic Proposal. Autonomy Research, Crookham Village. 2019. Available online: http://autonomy.work/ portfolio/the-shorter-working-week-a-report-from-autonomy-in-collaboration-with-members-of-the-4-day-week-campaign/ (accessed on 1 September 2020).

57. Braun, V.; Clarke, V. Using thematic analysis in psychology. Qual. Res. Psychol. 2006, 3, 77-101. [CrossRef]

58. Boyatzis, R. Transforming Qualitative Information: Thematic Analysis and Code Development; Sage: Thousand Oaks, CA, USA, 1998.

59. Fereday, J.; Muir-Cochrane, E.C. Demonstrating Rigor Using Thematic Analysis: A Hybrid Approach of Inductive and Deductive Coding and Theme Development. Int. J. Qual. Methods 2006, 5, 80-92. [CrossRef]

60. Hechanova, R.M.; Alampay, R.B.; Franca, E.P. Empowerment, job satisfaction and performance among Filipino service workers. Asian J. Soc. Psychol. 2006, 9, 72-78. [CrossRef]

61. Kasser, T.; Sheldon, K.M. Time Affluence as a Path toward Personal Happiness and Ethical Business Practice: Empirical Evidence from Four Studies. J. Bus. Eth. 2008, 84, 243-255. [CrossRef]

62. Henning, R.A.; Jacques, P.; Kissel, G.V.; Sullivan, A.B.; Alteras-Webb, S.M. Frequent short rest breaks from computer work: Effects on productivity and well-being at two field sites. Ergonomics 1997, 40, 78-91. [CrossRef] [PubMed]

63. Taylor, W.C. Booster Breaks: An Easy-to-Implement Workplace Policy Designed to Improve Employee Health, Increase Productivity, and Lower Health Care Costs. J. Workplace Behav. Health 2011, 26, 70-84. [CrossRef]

64. Ryan, R.M.; Bernstein, J.H.; Brown, K.W. Weekends, Work, and Well-Being: Psychological Need Satisfactions and Day of the Week Effects on Mood, Vitality, and Physical Symptoms. J. Soc. Clin. Psychol. 2010, 29, 95-122. [CrossRef]

65. Sonnentag, S.; Mojza, E.J.; Binnewies, C.; Scholl, A. Being engaged at work and detached at home: A week-level study on work engagement, psychological detachment, and affect. Work Stress 2008, 22, 257-276. [CrossRef]

66. Kasser, T. Living both Well and Sustainably: A Review of the Literature, with Some Reflections on Future Research, Interventions and Policy. Philos. Trans. R. Soc. A Math. Phys. Eng. Sci. 2017, 375. [CrossRef] [PubMed]

67. Nyland, C. Reduced Worktime and the Management of Production; Cambridge University Press: Cambridge, UK, 1989.

68. Schor, J.B. Global equity and environmental crisis: An argument for reducing working hours in the North. World Dev. 1991, 19, 73-84. [CrossRef]

69. Ahuvia, A.C. Beyond the Extended Self: Loved Objects and Consumers' Identity Narratives. J. Consum. Res. 2005, 32, 171-184. [CrossRef]

70. Winston, A. Luxury Brands Can No Longer Ignore Sustainability. Harvard Business Review. 2016. Available online: https: //hbr.org/2016/02/luxury-brands-can-no-longer-ignore-sustainability (accessed on 1 August 2020). 